\title{
When times get tough
}

\author{
Simcha Jong \\ With the major economies around the world in recession, what strategic actions should you be taking?
}

\begin{abstract}
Turmoil in the financial markets is making the business environment for life sciences companies challenging. The situation is becoming particularly difficult for those involved in running small firms and startups. Although many of the factors in a financial downturn are out of your hands, history suggests several simple steps to steel your business against the long economic winter that lies ahead.
\end{abstract}

\section{Short-term liquidity: finding new sources of money}

Of all the issues troubling small biotech firms today, liquidity has become the most important, for two reasons. First, the initial public offering (IPO) as a near-term exit option for investors has been taken off the table. According to data from Jefferies and Company of New York, capital raised by publicly traded biotech companies was down $62 \%$ over the first 9 months of 2008 as compared with the same period in 2007. Across all industries, 2008 was the worst year for IPOs of venture-backed companies in at least 31 years. Most observers agree that the IPO window will not reopen anytime soon.

Second, available venture capital is dwindling fast as a growing number of investors are unable to make good on commitments to existing venture capital funds. Moreover, funding that venture capitalists do have at their disposal is mostly frozen into existing investments, and exiting from these investments has become ever more difficult.

This means a liquidity problem for many biotech firms. According to data compiled by the Biotechnology Industry Organization, 25\% of the 370 public US biotech companies have less than six months' worth of cash. Among privately owned biotech firms, this figure is

Simcha Jong is a lecturer at the Department of Management Science and Innovation, University College London, Gower Street, London WC1E 6BT, UK.

e-mail: s.jong@ucl.ac.uk likely to be much higher. This makes securing access to cash and credit lines an immediate priority. How should you go about it, and what are your options?

If you need short-term liquidity, you should first seek support from existing private investors-an option that, surprisingly, companies today often overlook. Existing investors already have a stake in a firm's future. In addition, bringing in new investors during periods of financial duress usually comes at a comparatively high price to existing investors in terms of the dilution of their equity. Therefore, existing investors have an interest in providing bridge loans or other types of short-term cash infusion to give managers time to get their act together and reposition their firms.

Second, you may be able to monetize some of your firm's assets. Several specialized financial firms, such as Paul Capital Healthcare of San Francisco, offer financing to early-stage biotech firms against future royalty payments. If you are fortunate enough to be managing a firm with products reaching the clinic, then pursue investors such as Symphony Capital of New York and Cowen Healthcare Royalty Partners of Stamford, Connecticut, as well. These firms specialize in offering financing against existing or future revenues associated with specific clinical development programs. Finally, firms such as Oxford Finance in Alexandria, Virginia, that specialize in offering loans to companies in the life sciences industry might help you access credit lines specifically tied to equipment purchases.

Third, consider a reverse merger. These have become an increasingly popular option for biotech firms seeking to shore up their liquidity. Biotechs with promising pipelines often team up with publicly traded firms with plenty of cash reserves but weak pipelines (see Box 1). However, as the number of reverse mergers increased over 2008, the number of public targets for such mergers has decreased, so finding an appropriate partner might be tough.
Fourth, you should exploit the growing number of funding opportunities outside the commercial sector. Apart from enhancing your cash position and credibility in the marketplace, funding from the government or charities generally comes with the added benefit of not diluting equity. As with recently ailing banks, the best hope for you to stay afloat may well be turning to the government for help. Public funding agencies have continued to expand their role in biotech during the current downturn, particularly in fields such as stem cell research, regenerative medicine and cancer research. Data from BioWorld show that public funding agencies committed more than \$275 million in support to biotech firms from March to October last year.

You should also approach nonprofit foundations, particularly if your company works in a therapeutic niche area not served by the major pharmaceutical companies. In addition to the larger foundations such as the Wellcome Trust in London and the Bill and Melinda Gates Foundation in Seattle that have shown a growing interest in supporting research and development in biotech, foundations dedicated to specific disease areas have become receptive to funding promising compounds in these areas. According to data from Thomson CenterWatch, funding by patient advocacy groups has increased 13-fold over the level in 2000. For example, the Cystic Fibrosis Foundation of Bethesda, Maryland, has awarded biotech companies more than $\$ 300$ million over the past 10 years ${ }^{1}$.

\section{Recession-proofing your firm: repositioning for long-term success}

Once you've gotten some much-needed cash back into your organization, it's time to strategically reorient your business. Convene a meeting among your top managers, and spend time reassessing the firm's long-term objectives and planning. You should reach a consensus about where your company should be in the life 
sciences industry value chain, and then work out a detailed action plan that will lead it in that direction.

The reduced funding available these days coupled with the collapse of several exit options means that you must be more focused than ever in setting long-term objectives. Small biotech firms are notoriously unfocused, with their futures hedged against multiple business opportunities. Many follow two-track strategies, focusing both on the further development of their drug discovery platforms and on various downstream clinical development projects. Before the meeting, prepare a comprehensive list of your firm's current programs and activities. Go over each of the different project and activity items on the list during the meeting and prioritize by assessing for each item how, given the firm's limited resources, it contributes to long-term objectives.

Coming out of such a meeting, the strategic focus of the firm is most likely also going to be different from what it was beforehand. The new strategy will need to neutralize the effects of the changed funding environment by avoiding the financial markets and focusing on growth plans that rely on alternative sources of funding.

For example, firms with innovative drug discovery platforms are currently in favor with pharmaceutical firms. Although the R\&D productivity of pharma firms remains abysmal, they continue to have significant cash reserves and excellent credit ratings. As a result, spending by pharma on discoverystage deals has skyrocketed and can represent an important business opportunity for you. Data from Signals Magazine show that 6 out of 13 \$1-billion-plus biopharma deals in 2007 were pure 'discovery deals' (deals that did not involve compounds in clinical trials). Another four were 'discovery oriented' (involving stillto-be-discovered compounds, as well as compounds in clinical trials). The consolidation wave that is set to hit the biotech industry is in many ways a race to create the product offerings that will drive improvements in the R\&D performance of pharma firms over the coming years.

Therefore, your firm will be among the winners if you manage to focus on consolidating existing expertise, intellectual property and skills in integrated 'technology suites' for the R\&D organizations of pharmaceutical firms. Maintaining a wait-and-see approach toward the consolidation wave will leave you with a dwindling set of options. You should thus try to catch this wave sooner rather than later, and the development of a partnering strategy should be

\section{Box 1 Cash + pipeline = new company}

Publicly traded firms that encounter unexpected hurdles in the clinical trials process sometimes end up with a large pile of cash without projects to spend it on, and they therefore make desirable merger targets. The recent reverse merger announced in September 2008 between publicly traded Novacea, of South San Francisco, and Transcept Pharmaceuticals, of Point Richmond, California, is a good example. Novacea had to abandon phase 3 trials for its core clinical asset, the prostate cancer drug Asentar, and was looking for new investment projects for its $\$ 84$ million in cash reserves. The management of cash-strapped Transcept convinced Novacea's management that gaining final-stage approval and launching Transcept's insomnia drug Intermezzo would put these reserves to good use.

In a similar deal, privately held and cash-strapped ARCA Biopharma, of Broomfield, Colorado, announced in September its intention to merge with publicly traded Nuvelo of San Carlos, California. Nuvelo had $\$ 76$ million in cash at the end of June but no meaningful pipeline following the failure of alfimeprase in clinical trials. ARCA Biopharma, in contrast, had a heart failure drug, bucindolol, for which it had filed a new drug application that is under consideration by the FDA.

To make a reverse merger work, it is particularly important to gain support from shareholders in the cash-rich 'shell' company. Shareholders' concerns about the valuation of the cash reserves that go into the new company form a key obstacle in such mergers. Failure to preemptively address these concerns early on will mean significant problems for the merger down the road. This is how the reverse merger, announced in November 2008, between cash-strapped Archemix, of Cambridge, Massachusetts, and publicly traded NitroMed, of Lexington, Massachusetts, ran into trouble. Nitromed had sold its most important clinical asset for a one-off $\$ 24.5$ million payment in cash and, unlike Archemix, had no promising compounds in the pipeline to spend this cash on. However, NitroMed's shareholder, Chicago-based Deerfield Management, disputes the value that Archemix is able to contribute to the new combination and is trying to block the merger. It instead wants to liquidate NitroMed's assets and distribute the firm's cash reserves directly to shareholders.

central in any action plan. You should identify potential partners that hold complementary technologies and lay the basis for an exploration of 'horizontal mergers' that will broaden both your drug discovery and development platforms.

This isn't possible for everyone, of course. In particular, if your firm is organized around a virtual business model or focused on a pharmaceutical niche market, then you might have a problem. So far, these are the companies among the first to move into administration. Nevertheless, there are modes of action for even these firms to avoid bankruptcy and salvage shareholder value (see Box 2).

\section{Your key stakeholders}

Your investors are probably going to pressure you to slash costs, regardless of any strategic realignments you initiate. There are a range of pitfalls associated with cutting costs. To get your business through an economic crisis, you're likely to need to convince key stakeholders, such as your employees, partners and customers, to make sacrifices. However, indiscriminate cost cutting potentially alienates these stakeholders. To avoid harming the firm's long-term strategic position, adhere to several simple principles.

Have a plan. Make any necessary cutbacks sooner rather than later. However, one of the worst mistakes possible is asking key stakeholders to make sacrifices without presenting a clear plan for how those sacrifices will help secure the firm's future. Seemingly arbitrary measures, such as across-the-board budget cuts or requests to trim the budgets of different departments, may create an image of management as incompetent and lost. Be specific.

Transparency. It is particularly important to keep suppliers, partners and customers on board during uncertain times. The economy is making it hard on everyone right now, and survival is largely tied to your success in mobilizing stakeholders behind the new direction. It is therefore advisable to intensify communication with partners by providing regular updates and by being open about the progress you're making in your realignment process. In addition, efforts to strengthen ties with key stakeholders during difficult times often translate into competitive advantages once economic conditions improve.

Negotiate. The economic turmoil is going to decrease demand for key services and products, which means the negotiating position of buyers will strengthen. You will have a number of 
opportunities to renegotiate payment terms. For example, the economic slump has put significant downward pressures on prices of office leases, creating an opportunity to renegotiate tenancy agreements. This could save you considerable money.

Use equity rather than cash. One strategy to preserve cash while also offering key stakeholders an interest in the success of the company is renegotiating terms of contracts so that payments are made in equity rather than cash. Some firms put into effect voluntary salary reduction programs, in which employees may opt to receive a part of their remuneration in equity instead of cash. Hemispherx BioPharma, of Philadelphia, announced in December that it will be using restricted stock to pay up to half the salary of its senior staff members. Consider this option for your own firm.

Layoffs. Management often uses layoffs to signal that it is in control and doing 'something' about the dire situation a firm is in. Although such announcements often have a positive short-term effect on investor confidence, research shows that forced redundancies often have a negative long-term impact on a firm's performance ${ }^{2}$. Apart from the loss of important skills, expertise and experience, redundancies often lead to a breakdown in trust between management and the employees who are left behind. As a result, you could face problems retaining key employees after forced redundancies. Try for voluntary redundancies, salary reduction programs and initiatives through which employees are hired as external consultants-in many cases these are preferable.

If forced redundancies are unavoidable, you should keep several guidelines in mind. First, it is imperative to cut staff once and to make sure such cuts do not drag on. There are few things more damaging to morale than a work environment in which there is a constant threat of further dismissals. Second, communicate clearly how layoffs (and decisions to retain certain employees) link into a long-term stra-

\section{Box 2 Survival tips for niche firms}

If you are a manager of a more development-oriented biotech firm without cash and income to fund clinical R\&D, you face a particularly hostile business environment. A key priority at this moment should be to make an assessment of what other companies your clinical assets may be valuable to and explore two strategic options.

First try to turn existing partners into buyers. In many cases, they have a stake in the continuity of your operations and an interest in increased control over your assets. As a result, existing partners are often willing to pay market premiums for your business.

This has happened several times in recent months. GeneLabs Technologies in Redwood City, California, in October convinced partner GlaxoSmithKline, of London, to buy it at a price that included a $565 \%$ market premium. Memory Pharmaceuticals in Montvale, New Jersey, in November convinced its partner F. Hoffmann-La Roche, of Basel, Switzerland, to buy it at a $319 \%$ market premium.

If you have a richer pipeline but not the cash to get any of your products to the market, you should pursue long-term partnership deals with more mature biotech or pharma companies that have significant cash reserves and complementary clinical assets. Under such deals, of which the original Genentech-Roche partnership is the best-known example, an investment is made by the larger firm that gives the biotech firm time and resources to move key compounds through the pipeline. In exchange, the biotech gives up an equity stake and a chunk of the commercialization rights related to its most promising compounds (usually outside its home market).

An example is the November deal between cash-strapped Infinity Pharmaceuticals, of Cambridge, Massachusetts, and privately held Purdue, of Stamford, Connecticut, and its Basel-based affiliate Mundipharma. In the deal, Purdue/Mundipharma will cover Infinity's $R \& D$ expenses until the end of 2013 in exchange for an equity stake in Infinity and commercialization rights on most of Infinity's pipeline outside the United States. Infinity maintains commercialization rights for the US market.

tegic plan. This will strengthen workers' confidence in your ability to lead the firm forward. Moreover, it empowers employees who remain during a period of uncertainty and turmoil. Third, it is important to remember that how you interact with those laid off has a direct impact on how survivors view their future. Therefore, magnanimous layoff packages and procedures often repay themselves through the goodwill they create among the remaining employees.

\section{The silver lining}

Despite the funding squeeze and the likely slowdown of the broader economy, the longterm prospects for the biotech industry as a whole remain good. Consumers who are the end users of products of biotech firms are not (yet) cutting back on healthcare spending. In fact, markets for healthcare products are, for obvious reasons, among the most recessionproof of markets. Moreover, demand by the major pharma firms for the innovative technologies developed by biotech firms remains strong. Finally, the wave of consolidation hitting the industry means that firms able to weather the current economic slowdown will face less competition in the future. If you recognize the challenges that lie ahead and adjust your financial and strategic plans accordingly, you're likely to be rewarded.

1. Harris, M. Philanthropy and nonprofit dollars drive up discovery value. BioWorld Today 514 October (2008).

2. Mishra, K.E., Spreitzer, G.M. \& Mishra, A.K. Preserving employee morale during downsizing. Sloan Management Rev. 39(2) 83-95 (1998). 